\title{
Elementos filosófico-religiosos em torno da compreensão de liberdade em Melanchthon a partir da literatura secundária recente
}

\author{
Eduardo Gross*
}

\section{Resumo}

Melanchthon, na Universidade de Wittenberg, era professor da Faculdade de Artes, e, assim, de filosofia. A sua filosofia teológica assumiu elementos do pensamento antigo e escolástico: Um pano de fundo platônico, uma psicologia aristotélica e uma retórica ciceroniana foram alguns dos elementos que caracterizaram a sua elaboração filosófica eclética importantes para se compreender sua reflexão sobre a liberdade. O artigo apresenta algumas controvérsias e os principais resultados das pesquisas dos últimos anos relativas a sua reflexão filosófica sobre o âmbito da religião e a liberdade humana Palavras-chave: Melanchthon, liberdade, ecletismo, renascimento, humanismo

\section{Philosophical-Religious Elements on the Understanding of Freedom in Melanchthon According to Recent Secondary Literature}

\section{Abstract}

Melanchthon, in the University of Wittenberg, was professor of the Faculty of Arts, and so, of Philosophy. His theological philosophy assumed elements of antique and scholastic thought: Platonic background, Aristotelian psychology, Ciceronian rhetoric were some important elements that characterized his eclectic philosophical construction and are key to understand his conception of freedom. The article presents some controversies and the main results of the last years researches about his philosophical reflection on the realm of religion and human freedom.

Keywords: Melanchthon, freedom, eclectics, Renaissance, humanism

* Graduação e Doutorado em Teologia pela EST-RS; Professor da UFJF, com atuação nos Programas de Pós-Graduação em Ciência da Religião e Filosofia; e-mail: eduardo.gross@ ufjf.edu.br; currículo: http://lattes.cnpq.br/2654429053268264. 


\section{Elementos filosófico-religiosos en torno a la comprensión de la libertad en Melanchthon a partir de la literatura secundaria reciente}

\section{Resumen}

Melanchthon, en la Universidad de Wittenberg, era profesor en la Facultad de Artes, y, así, de filosofía. Su filosofía teológica asumió elementos del pensamiento antiguo y escolástico: Un pano de fundo platónico, una psicología aristotélica, una retórica ciceroniana fueron algunos de los rasgos que caracterizaran su elaboración filosófica ecléctica importantes para la comprensión de su reflexión sobre la libertad. El artículo presenta algunas controversias y los principales resultados de las pesquisas de los últimos años relacionadas con suya reflexión filosófica sobre el ámbito de la religión e la libertad humana.

Palabras llave: Melanchthon, libertad, eclecticismo, Renacimiento, humanismo, humanismo

\section{A estrutura racional de fundo}

\subsection{Conhecimento e Espírito}

Na história da pesquisa sobre Melanchthon a questão da herança filosófica determinante foi sempre bastante controvertida. A pesquisa mais recente mostrou uma certa maioria convergente em relação à importância do pensamento platônico no desenvolvimento inicial do pensamento dele. Cabe destacar aqui as pesquisas históricas de Wilhelm Maurer. Ele parte do fato de que Melanchthon foi educado no círculo de influência de Reuchlin, onde se cultivava um humanismo que manifestava estreitas relações com o neoplatonismo florentino, uma vez que o próprio Reuchlin teve oportunidade de estudar na Itália. Maurer parece exagerar um pouco em alguns aspectos: Praticamente ninguém segue suas sugestões a respeito de influências pitagóricas, que eram importantes para Reuchlin, sobre Melanchthon, e o reconhecido gosto deste pela astrologia normalmente retrata mais uma característica geral dos humanistas da época do que algo que se devesse necessariamente a elementos esotéricos daquele círculo em particular. Em todo caso, a ideia de que na base da concepção astrológica estejam por um lado a noção de uma ordem racional cósmica e por outro uma relação estreita entre este macro-cosmo e o micro-cosmo humano é uma das características marcantes da época. Mas mais significativa na recepção da pesquisa de Maurer se mostrou a sua concepção de que a teologia do Espírito (Geist) de Melanchthon tenha recebido uma influência importante da 
tradição platônica. A questão destacada a esse respeito é que Melanchthon, em sua teologia, teria expresso em termos cristãos - com a noção da dádiva do Espírito Santo - a conexão da mente humana com a razão universal de feitura platônica (MAURER, 1969, Bd. 2, S. 387, 391).

Siegfried Wiederhofer argumenta num sentido semelhante, ao tratar do conceito de revelação de Melanchthon. Mesmo que sua pesquisa privilegie a perspectiva teológica, as suas informações sobre os elementos filosóficos em Melanchthon são bastante significativas. Além de, como Maurer, mencionar a teologia do Espírito como herança platônica, Wiederhofer também menciona a terminologia usada na cristologia de Melanchthon como reveladora nesse sentido, quando este fala de Cristo como ektypos ou como sermo do Pai (WIEDENHOFER, 1976, p. 122-126). Enquanto pensador cristão, entretanto, Melanchthon expressou a imperfeição da participação da razão humana na ordem racional universal a partir da noção teológica da queda. No desenvolvimento do seu pensamento o grau em que essa participação pode se realizar foi variando, o que naturalmente é significativo para a questão em exame. Em todo caso, o que Melanchthon fez foi utilizar uma distinção teológica luterana (entre lei e evangelho) para conceber a razão como dizendo respeito ao âmbito da lei, enquanto que a graça divina foi entendida como própria ao âmbito do evangelho. Dessa forma, ao mesmo tempo em que afirmava uma participação da razão humana no conhecimento da ordem geral pela lei, ele reconhecia a necessidade teológica de um outro tipo de conhecimento, revelado, para uma compreensão do que diz respeito propriamente ao âmbito espiritual (WIDENHOFER, 1976, p. 188-193).

Um ponto alto da argumentação a respeito da importância do elemento platônico no pensamento de Melanchthon é representado pela defesa que Günter Frank faz da importância do exemplarismo e da teoria da metéxis na estrutura do seu pensamento. Também em sua argumentação a concepção sobre o Espírito é central, no sentido da afirmação de uma "familiaridade essencial" (Wesensverwandschaft) entre o Espírito divino e o humano (FRANK, 1995, p. 90, 93-95). Teologicamente, essa concepção se fundamenta na teologia da criação. Mas, para Frank, o fundamental é o fato de que Melanchthon se distingue da abordagem escolástica ao se afastar de uma reflexão que dê importância ao aspecto ontológico dessa relação entre o divino e o humano. Nesse sentido, ao invés de uma participação no ser divino, aqui só é acentuada uma participação no espirito (ou na mente - Geist). Isso é importante porque possibilita uma fundamentação teo-racionalista 
da reflexão humana - da filosofia e das ciências em geral (FRANK, 1995, p. 99-102; 305-314).

Uma contestação mais recente quanto à importância da tradição platônica para Melanchthon foi apresentada por Charles Peterson. Este afirma que, se a tese de uma centralidade do elemento platônico em Melanchthon fosse aceita, então seria necessário afirmar a incongruência do pensamento deste. Isso porque na verdade há elementos de várias tradições filosóficas assumidas por ele, de modo que seria preferível falar só de ecletismo no seu caso (PETERSON, 2012, p. 301). Entretanto, Peterson parece não reconhecer que Frank certamente afirma a presença de elementos diversos no pensamento de Melanchthon, mas que o mais importante é sua advertência de que falar simplesmente de ecletismo ainda não significa muita coisa - também as tradições platônica e aristotélica se construíram ecleticamente. Porque o que realmente importa é mostrar como os vários elementos coletados são organizados, qual é o princípio organizador que permite a sua configuração (FRANK, 1995, p. 15-19, 181). Dessa forma, a ideia de que esse platonismo de fundo funcione nesse sentido ainda não foi derrubada.

\subsection{Lei natural inata}

Responsável pelo deslocamento de uma metafísica do ser para uma esfera mental, por sua vez, é a leitura da tradição platônica intermediada por Cícero. A importância de Cícero para Melanchthon, para o contexto da Reforma e do humanismo renascentista em geral é bem conhecida (cf. FRANK; EUSTERSCHULTE, 2018). Particularmente no caso de Melanchthon, também já há praticamente um consenso geral a esse respeito quanto a vários aspectos de sua reflexão: a compreensão da racionalidade, a importância da retórica, a preocupação com a ética e mesmo a intermediação exercida na recepção de outros pensadores da Antiguidade. Nesse ponto, entretanto, cabe destacar a importância de Cícero para o desenvolvimento do conceito de "lei natural" em Melanchthon.

O conceito de lumen naturae é usado por Cícero, por exemplo, nas Tusculanae Disputationes, 3.2. Ele faz referência a um conhecimento natural de princípios morais. Trata-se ali de elementos inatos (sementes) que permitem o reconhecimento da virtude e o encaminhamento da vida de acordo com ela. E no De natura deorum 2.78-79 afirma que o ordenamento do que é correto e a compreensão do que é prudente na mente humana deve ter origem divina (cf. GERHARDS, 155, p. 123, n. 77). O que Melanchthon faz, então, é assumir 
essa compreensão em conjunção com a noção anteriormente exposta do parentesco entre espírito (ou mente - Geist) humano e divino, configurando-o de acordo com a teologia cristã da criação. Para esse conhecimento impresso ${ }^{1}$ na mente humana universalmente por ocasião da criação ele usa o nome de lei natural.

Embora essa expressão também já fosse utilizada por outros, cabe destacar que no caso de Melanchthon há uma conjunção da expressão com o termo lei da distinção teológica luterana entre lei e evangelho. Por isso, por um lado a expressão serve para designar os fundamentos internos para o conhecimento e a prática da virtude, como em Cícero. Mas, por outro, ela também recebe um emprego muitíssimo mais amplo, servindo para fundamentar a possibilidade natural humana de desenvolvimento de todo e qualquer conhecimento. Nesse sentido, aparecem em sua obra como exemplos de forma constante o conhecimento matemático, a distinção entre o bem e o mal e a estrutura lógica da argumentação. O próprio Melanchthon se refere à lei moral como eterna e transmitida por ocasião da criação no seu comentário a De officiis (FRANK, 1995, p. 147, n. 403). Entretanto, diferentemente de Cícero, em Melanchthon, como na tradição cristã em geral, não se aceita a concepção da imanência da divindade no mundo. ${ }^{2}$ Desta forma, esta concepção é assumida em conexão com o exemplarismo platônico, típico no cristianismo medieval. Mas a novidade desta formulação é que Melanchthon deixa de lado um modelo centrado numa preocupação metafísica e adota um que espelha a perspectiva retórica. Trata-se de um processo em que a mente conceptualiza o que percebe a partir de ideias que lhe são inatas (cf. FRANK, 1995, p. 116-122; 128-129; 332-333, n. 481; MAURER, 1969, v. 2, p. 288-296).

\subsection{Implicações para o tema da liberdade humana}

A concepção da estrutura racional da realidade e a sua expressão no ser humano representam pressupostos básicos para a discussão da questão da liberdade que aparece no pensamento de Melanchthon. Como estas noções são colocadas em conexão com a sua estrutura teológica específica

\footnotetext{
Os termos privilegiados por Melanchthon para expressar essa sua formulação são "impresso", "ínsito" e "inato".

2 GERHARDS, 1955, p. 43 aponta para a tradição anterior que também se serviu da exegese de Romanos para uma noção de lei natural: Tertuliano, Irineu, Ambrósio, Agostinho, sendo que este último também já usa Cícero e Plotino. Para o desenvolvimento do conceito assumido por Melanchthon durante o período medieval, cf. FRANK, 1995, p. 156 e GERHARDS, 1955, p. 46-47.
} 
de pensamento, grande parte da discussão em torno da liberdade humana se dará em conexão com o grau em que esta capacidade de conhecimento inata, representada por um lado pelo parentesco entre o espírito (ou a mente - Geist) humano e o divino e por outro lado pelo caráter inato de certos conhecimentos, se manteve ou não após a queda original no pecado. A tendência geral é de que Melanchthon afirme uma capacidade maior de manutenção desses conhecimentos no âmbito que ele chama de lei (a estrutura exterior da vida, a vida pública, os conhecimentos científicos) e uma capacidade praticamente nula da mesma no âmbito que ele chama de evangelho (a interioridade existencial, os conhecimentos relativos a verdades reveladas e, principalmente, a mensagem da justificação gratuita do ser humano diante de Deus). Entretanto, ao mesmo tempo em que ele afirma que o pecado afetou todos os âmbitos do conhecimento, que assim sempre dá mostras de imperfeição, ele também varia em seus escritos quanto à avaliação do que tenha restado de capacidade humana de conhecimento, mesmo na esfera moral e até na capacidade subjetiva de aceitação da graça divina.

\section{Aceitação e rejeição do determinismo}

\subsection{O determinismo nos Loci theologici de 1521}

A publicação dos Loci theologici de 1521 marca o ponto alto do determinismo no pensamento de Melanchthon. Sua aproximação com Lutero no período imediatamente anterior está relacionada com a configuração dessa obra. Nesse contexto, o determinismo era entendido como correlativo à afirmação da graça divina como base exclusiva da justificação. Em todo caso, a publicação de 1521 antecede o debate literário sobre a questão do livre arbítrio entre Lutero e Erasmo, de modo que no Servo arbitrio Lutero pode fazer referência aos Loci de Melanchthon como formulação exemplar contra a posição de Erasmo (cf. GREYBILL, 2010, p. 81-89).

Apesar disso, a perspectiva adotada nesta obra não se deve simplesmente a Lutero. A concepção antropológica que Melanchthon apresenta, por exemplo, divide a pessoa em duas faculdades: a capacidade de conhecer as coisas (a razão, a percepção) e a capacidade de seguir o que é conhecido (vontade, paixão, desejo). Esta divisão se encontra no De theologia mystica de Gerson, e se distingue da concepção tripartite entre corpo, alma e espírito que é adotada, dentre outros, por Lutero. Melanchthon, a partir dessa divisão antropológica, da adoção de um raciocínio intelectualista e de uma 
leitura bíblica que privilegia a direção divina no mundo adota uma postura em que rejeita posturas menos deterministas da tradição anterior. Explicitamente, o seu argumento é que as Escrituras afirmam esse determinismo, enquanto que a razão humana arrogantemente se engana a respeito de sua própria capacidade (HOLM, 2017, p. 396-397). Nesse contexto, a defesa que ele empreende da concepção de Valla merece ser destaca por ser sintomática da mudança de posicionamento que ocorrerá no futuro (MELANCHTHON CR 21, 89).

Entretanto, apesar da argumentação explicitamente escriturística, há toda uma fundamentação psicológica elaborada por ele para a falta de liberdade da vontade. ${ }^{3}$ A sua teoria dos afetos enquanto forças desordenadas que agem no interior da pessoa e impossibilitam uma ação efetivamente livre da vontade representa uma argumentação não teológica, mas filosófica do determinismo (MAURER, 1969, v. 2, p. 267). Ainda que a causa do estado caótico dos afetos interiores seja a queda no pecado e a solução seja o reordenamento dos mesmos a partir da ação do Espírito divino (MÜLLER, 2017, 128-133), esta concepção antropológica não tem uma origem imediatamente teológica, mas retoma elementos da psicologia filosófica de Aristóteles transmitidos via Cícero.

Gerhards (1955, p. 41) nota como nos Loci de 1521 há uma contradição entre, por um lado, a ideia de uma lei natural e a consequente liberdade em assuntos exteriores e, por outro, o determinismo geral que caracteriza o escrito. Essa observação é importante, uma vez que ela mostra um

3 Greybill (2010, p. 91-97) é um exemplo dentre autores que tendem a diminuir a importância do papel da argumentação filosófico-psicológica desenvolvida por Melanchthon. Na sua opinião, esta é acrescentada de forma somente subsidiária à interpretação bíblica. É verdade que a Bíblia é critério de verdade para Melanchthon, inclusive em matéria não teológica. Entretanto, interpretações como a de Greybill tendem a obscurecer o conhecimento que Melanchthon tinha da tradição filosófica e teológica anterior, assim como a influência que este conhecimento teve na própria interpretação bíblica desenvolvida por ele. Com relação a outros escritos, intérpretes como Greybill também tendem a acentuar o caráter secundário dos temas filosóficos em Melanchthon, como a ausência do tema dos afetos em Annotationes in Romanos de 1522 (GREYBILL, 2010, p. 99-100) ou a ênfase com preocupações pastorais como motivo para a cautela posterior na tematização do determinismo (GREYBILL, 2010, p. 104-105). Isso pode até ser verdade, mas além dessas observações terem um caráter um tanto especulativo, não é necessário de modo algum diminuir a importância dos temas filosóficos em Melanchthon para dar relevo à perspectiva teológica em sua obra, uma vez que esta evidentemente já tem sua importância garantida. A perspectiva do presente artigo, nesse sentido, busca resgatar a importância que o conhecimento da sua reflexão filosófica tem para a compreensão de Melanchthon. 
motivo estrutural para mudanças que o texto sofre já no ano seguinte, na tentativa de minorar este problema (cf. GERHARDS, 1955, p. 46). Também Greybill (2010, p. 95) percebe que a formulação de 1521 relativa ao tema do determinismo gera problemas que levarão a mudanças nos Loci já em 1522. Entretanto, num outro texto, Annotationes in Romanos, também de 1522, o determinismo ainda se mostra dominante. Parece que a importância teológica dada ao tema da predestinação pode ter levado a expressar tal determinismo, já que ali aparece inclusive uma defesa da dupla predestinação (GREYBILL, 2010, p. 97-97; 100-102).

Como aqui o interesse principal está na questão da liberdade humana, não se dedicará uma atenção maior à questão do determinismo cósmico. Basta registrar que a tendência geral da argumentação presente nos Loci de 1521, afora a contradição assinalada por Gerhards referida acima, tende a afirmar tal determinismo universal. Especialmente as interpretações das referências bíblicas citadas no texto para fundamentar o conceito de predestinação, a providência divina e a contestação do acaso apontam nessa direção.

\subsection{Conflitos e necessidade de decisão}

Além da contradição expressa acima, também o contexto histórico obrigou Melanchthon a rever a sua exposição. Há um consenso geral na pesquisa de que acontecimentos históricos motivaram uma revisão da postura de Melanchthon diante do determinismo expresso anteriormente. Para Maurer (1969, v. 2, p. 425), as concepções sobre predestinação, vontade, assim como a teologia do Espírito não estavam suficientemente amadurecidas na formulação de 1521, e justamente os desafios que se apresentaram nesse período, representados primeiro pelo movimento iconoclasta e depois pela revolta dos camponeses, teriam tornado isso claro. A questão é que uma concepção de imediaticidade da ação do Espírito Santo sobre os afetos não fornecia um critério a respeito de revelações espirituais. Mais tarde, o movimento camponês colocava em cheque a ordem social tradicional, cuja estabilidade, como os humanistas em geral, também Melanchthon prezava. Nesse sentido, as suas formulações sobre a vida agradável a Deus vivida imediatamente a partir da fé não deixavam espaço para a necessidade da educação, reflexão e decisão ética. ${ }^{4}$

4 Maurer vai ainda mais longe nessas suas considerações. Para ele esses eventos foram ocasião
para o surgimento de uma crise vocacional. Essa teria sido a razão para Melanchthon não
aceitar trocar sua vinculação com a Faculdade de Artes pela Faculdade de Teologia, como
era a vontade de Lutero (cf. MAURER, 1969, Bd 2, capítulo 8). O caráter hipotético dessa 
Assim é que já em 1522 Melanchthon aprofunda a concepção da liberdade humana no âmbito da exterioridade, mantendo um domínio divino geral. Ele reformulou as partes sobre livre arbítrio e liberdade cristã, reordenou a apresentação desses temas e diminuiu a contradição entre a liberdade humana no âmbito da vida civil (exterioridade) e o determinismo geral, especialmente na sua suma sobre o ponto em questão (GREYBILL, 2010, p. 111-113). Em 1523 ele aprofundou ainda mais essa exposição com o desenvolvimento da noção de dupla justiça, de modo que a liberdade humana ganhou importância no âmbito da vida civil, sendo que a incapacidade de liberdade se restringiu ao âmbito da justificação diante de Deus (GREYBILL, 2010, p. 125). Assim, Greybill (2010, p. 131) conclui que, após esse período, o determinismo foi abandonado e o tema da predestinação perdeu centralidade, passando a ser considerado objeto de especulação temerária (cf. tb. JUNG, 2017, p. 439-440). ${ }^{5}$

Outro evento importante na década de 1520 ligado à questão do determinismo é o debate literário entre Lutero e Erasmo sobre a questão do livre arbítrio. Este tema é um dos mais controversos na pesquisa. É notório que preocupações confessionais, orientações teológicas e posicionamento quanto a importância da filosofia no pensamento de Melanchthon desempenham um papel fundamental nas interpretações do período. Há quem a todo custo tente manter Melanchthon o mais próximo possível de Lutero e afastá-lo de simpatias erasmianas; há quem procure fazer exatamente o oposto; há quem queira apresentá-lo como um mediador. É possível sintetizar o que na pesquisa parece alcançar um certo nível de consenso da seguinte forma: No que diz respeito ao determinismo em geral, Melanchthon o rejeita e paulatinamente vai reformulando seu pensamento na direção de mostrar cada vez mais a sua contrariedade com relação a este aspecto; no que diz respeito à predestinação, de forma semelhante, ele vai abandonando a discussão do tema e considera temerário especular sobre ele; no que diz respeito à liberdade da vontade humana no âmbito civil e suas implicações

conjectura faz com que ela não encontre muitos seguidores. Alternativamente também é possível conjecturar que Melanchthon, apesar da simpatia pelo movimento da Reforma, consideraria igualmente importante manter a sua perspectiva humanista, cujas tarefas nos âmbitos filosófico, linguístico-literário, pedagógico e ético exigiam sua contribuição justamente na Faculdade de Artes.

5 Nesse mesmo contexto Greybill afirma também que a psicologia filosófica sobre os afetos perdeu importância, o que, entretanto, não se verifica, conforme a sua presença significativa até no Liber de anima, de 1553. 
para a capacidade intelectual e ética, há um progressivo aprimoramento da defesa da mesma, sempre com um tipo de lembrança dogmática de que também ela não é irrestrita, já que a existência humana se dá sob a queda; no que diz respeito à liberdade da vontade humana em relação à justificação diante de Deus, ele também se encaminhará no futuro a abrir um pequeno espaço para ela, ao afirmar que, para que a justificação ocorra, a pessoa não pode rejeitar a graça. Parece impossível e pouco produtivo tentar traçar linhas de influências pormenorizadas sobre cada um desses desenvolvimentos a partir simplesmente do debate entre Lutero e Erasmo, como muitas vezes é feito. Até porque essas linhas de desenvolvimento não se resolveram durante ou imediatamente após a controvérsia em questão. Possivelmente seja mais adequado considerar que Melanchthon chegou a sua própria formulação dessas questões a partir de convicções humanistas que já possuía antes do contato com Lutero, a partir de elementos teológicos luteranos que considerava fundamentais, a partir da reflexão que o debate dos argumentos de Lutero e Erasmo lhe propiciou e a partir de suas próprias pesquisas, particularmente no âmbito da retórica, da ética e da filosofia natural, respectivamente, da psicologia filosófica.

Uma das direções interpretativas na pesquisa pode ser exemplificada por Helmut Gerhards. Ele faz referência aos textos da Instrução aos visitadores, dos Scholia in Colossenses e do Comentarium a esta epístola. Destaca a defesa que Melanchthon faz da liberdade no âmbito civil (exterior) apesar da direção divina geral. Sua ideia básica é de que há uma mudança forte em relação ao determinismo afirmado nos Loci de 1521. Além disso, defende que a liberdade exterior e a ênfase na dependência interior em relação à graça não estão mais simplesmente em paralelo, mas há relação entre elas. Daí a defesa do conhecimento filosófico e da capacidade da ação moral, ainda que enfraquecida pelo pecado original e pela ação do diabo. Gerhards caracteriza esse processo como um retorno ao humanismo, aproveitando-se para tal de elementos da tradição patrística e escolástica. Ao mesmo tempo, quanto ao tema da justificação, afirma que Melanchthon em nada teria se afastado da concepção luterana (GERHARDS, 1955, p. 61-66).

A outra direção interpretativa pode ser exemplificada por Wengert, Greybill e Matz. Parece ser a ênfase numa abordagem mais puramente teológica que leva a este posicionamento distinto. Greybill procura mesmo contestar outros pesquisadores que afirmam uma proximidade de Melanchthon em relação a Erasmo, como Stupperich e Bayton. Ele 
acentua o distanciamento em relação a Erasmo a partir de 1522 como estabelecido (GREYBILL, 2010, p. 126-129). Toda a interpretação histórica de Wengert, por sua vez, destaca até mesmo um tipo de competição entre Erasmo e Melanchthon, encoberta pela civilidade cortês humanista, mas sem proximidade pessoal (WENGERT, 1998, p. 68-136; cf. tb. MAURER, 1969 , v. 2, p. 87).

\subsection{Contraposição a maniqueísmo e estoicismo}

A reflexão sobre a liberdade humana encaminhou também a rejeição de concepções filosóficas consideradas deterministas por Melanchthon. O problema da atribuição do mal a Deus é um dos elementos frequentemente citados por ele para fundamentar tal rejeição. Nesse sentido, é possível falar de uma motivação teológica para essa mudança de posição (cf. MELANCHTHON, 1989, p. 38-39; HOLM, 2017, p. 399; cf. tb. WENGERT, p. 80-81). ${ }^{6}$ Como este foi um argumento levantado por Cochlaeus contra os seus Loci de 1521 e por Erasmo contra Lutero, é importante ressaltar a disposição de Melanchthon a se reposicionar diante de críticas recebidas (cf. MAURER, v. 2, p. 265-266). Se é possível estabelecer tais críticas como motivação fundamental para a mudança, entretanto, não parece poder ser respondido fora do âmbito especulativo (cf. p. ex. GERHARDS, 1955, p. 73-75; GROSSE, 2017, p. 340).

Significativo para a mudança de posição quanto à liberdade humana é o fato de que o pensamento de Valla, que na primeira edição dos Loci em 1521 tinha sido tão defendido contra Eck, passou a ser explicitamente rejeitado na edição de 1535, sua primeira reformulação mais fundamental (cf. WENGERT, 1998, p. 143), como também ocorre em seus escritos filosóficos (p. ex. cf. GERHARDS, 1955, p. 86). Esta mudança de concepção se torna então definitiva, mas vai sendo afirmada de modo paulatinamente mais forte. No Liber de anima, por exemplo, ele ressalta - e afirma que está se contrapondo ao estoicismo - que Deus tem de ser pensado como completamente livre, e que ele também criou os anjos e o ser humano como seres livres. Embora, como visto, se possa dizer que a motivação para essa afirmação é teológica, o fato de Melanchthon citar autores da Antiguidade nesse contexto mostra que ele entende a sua argumentação como filosófica. No caso, ele faz referência à citação que Plutarco faz de Eurípides: "EI THEOÍ TI DRÔSIN AISCHRÓN, OUK EISİN THEOÍ.” A êfase na existência de uma certa liberdade nesse

\footnotetext{
6 No contexto teológico, também seria importante tomar em consideração a diferenciação
} em relação a Calvino (cf., p. ex., HOLM, 2017, 402). 
contexto, no caso inclusive em pessoas não cristãs, é motivada claramente pela preocupação com a ética. Pensar num determinismo absoluto significaria a possibilidade de atribuir a Deus aquilo que são más decisões humanas. Assim, o determinismo passou a ser visto como uma tentativa humana de fugir de suas próprias responsabilidades. O que, entretanto, é igualmente ressaltado nesse contexto, é que a liberdade de ação humana não implica nenhuma possibilidade de justificação diante de Deus - ou seja, a reflexão ética não interfere na concepção teológica fundamental, ainda que seja influenciada por ela (MELANCHTHON, CR 13, 158-161, a citação é da col. 159). De modo similar, Robert Kolb aponta para o uso de Tucídides e Platão nessa mesma linha de argumentação (KOLB, 2017, 116).

Os dois principais estudos que lidam com a discussão sobre Melanchthon e o determinismo são os de Helmut Gerhards e de Günter Frank. Gerhards (1955, p. 51-54; cf. referências adicionais na p. 123, n. 79 e 80) aponta que Melanchthon herda essa problemática do estoicismo, à medida que ali se afirmava um monismo racional metafísico estrito e uma antropologia dualista: determinismo universal e responsabilidade individual no caso de deliberação contrária à ordem racional universal. Ele desenvolve esta síntese a partir do caso de Crísipo. O estoicismo, nesse particular, se aproxima de Aristóteles, que afirma que o ser humano produz sua HÉXIS por vontade livre, por sua decisão (PROAÍRESIS) e merece o castigo por seu mal - diferentemente de Platão, para quem o mal se relaciona à falta de conhecimento. Há uma HEIMARMÉNE que governa o mundo, e ao ser humano cabe, pela sua vontade livre, seguir este processo responsavelmente. Semelhantemente a formulações melanchthonianas, esse determinismo se relaciona com a dinâmica dos afetos no ser humano.

Por outro lado, também o neoplatonismo representa um antecedente do mesmo problema. Se o mundo é emanação do NOÛS, como pode haver responsabilidade individual humana? Plotino defende que a pessoa tem possibilidade de decisão em relação a bem e mal, e com suas decisões se insere na ordem universal sem poder destruí-la, mas efetivando-a. ${ }^{7}$

\footnotetext{
O histórico que antecede Melanchthon elaborado por Gerhards (1955, p. 57-59, 96) inclui também os pensadores medievais, passando por Agostinho, Boécio e Tomás, por exemplo. Tal como os escolásticos, também Melanchthon mistura exposições filosóficas e teológicas, mas, em sua visão, Melanchthon claramente distingue as competências dessas disciplinas no que se refere ao conhecimento de Deus e, principalmente, à justificação (GERHARDS, 1955, p. 87-89). Também Frank (1995, p. 284-285) apresenta uma boa síntese, centrada no tema da providência.
} 
Um aspecto importante ressaltado por Gerhards é sua observação crítica no sentido de que Melanchthon simplificou demasiadamente as posições deterministas, como se o problema da relação entre uma determinação geral e a liberdade individual não fosse tematizada nessas tradições anteriores. $\mathrm{O}$ mesmo problema ocorre na sua avaliação com relação a Valla (GERHARDS, 1955, p. 86-87). Essa observação crítica de Gerhards é importante e pode ser relacionada com a exposição de Frank (1995, 218, cf. tb. p. 117, p. 157), que aponta para um deslocamento na questão do determinismo em função do pressuposto estoico da imanência do divino. Como a compreensão cristã da criação não coaduna com tal imanência, de fato a atribuição do determinismo ao divino apresenta nuances de significado importantes nos dois casos.

Dentre os elementos desenvolvidos pela escolástica, merece destaque a utilização da distinção entre necessitas consequentis e necessitas consequentiae. Vários medievais fizeram esta distinção, com alguma variação terminológica, na tentativa de harmonizar a noção da providência divina com a rejeição de um determinismo absoluto. Esta distinção, rejeitada por Lutero em seu debate com Erasmo, foi retomada por Melanchthon. Em conexão com este tema se desenvolve a argumentação sobre causa prima e causa secunda (GERHARDS, 1955, p. 69; FRANK, p. 240-244, 295-298).

Digna de nota é também a menção da referência de Melanchthon a ideias estóicas e maniqueias de Lutero, em carta ao príncipe eleitor (GERHARDS, 1955, p. 97-98; CR 9, 766). Nela Melanchthon afirma ter manifestado sua discordância em relação ao determinismo já em vida de Lutero, como de fato se observa desde a passagem dos anos de 1520 a 1530. Mas seria de acrescentar que este texto enfraquece a argumentação em favor da ideia de que apenas a morte de Lutero teria dado ocasião para manifestação da aceitação de crítica formulada por Erasmo (cf. GERHARDS, 1955, p. 73-74; cf. tb. a polêmica com Gallus, KOLB, 2017, p. 116).

Por outro lado, é necessário observar ainda que, apesar do abandono e da crítica ao determinismo, Melanchthon igualmente rejeitava um indeterminismo absoluto. Isso aparece expresso nos seus textos como contestação ao epicureísmo (FRANK, 1995, p. 286-287). É evidente que tal concepção entra em colisão com o princípio de Deus como criador, mantenedor e provedor do mundo e da humanidade. Além disso, num âmbito particularmente filosófico, também colide com a ideia de ordem, tão importante tanto na apreciação que Melanchthon faz da razão quanto na sua concepção de ética social. 


\subsection{Implicações para o tema da liberdade humana}

O momento histórico entre a publicação da primeira e a da segunda versão de seus Loci (1521 e 1535), em que se dá a mais significativa mudança em seu pensamento, particularmente no que diz respeito ao determinismo, é também um dos momentos mais discutidos pela pesquisa. Trata-se de um ponto complexo, uma vez porque há um processo de transformação intenso na própria argumentação de Melanchthon, mas, por outro lado, também porque a leitura que é feita dos textos é fortemente afetada por elementos como preocupação com confessionalidade, preferências teológicas, simpatias filosóficas, postura diante do humanismo. Fato é que há um processo de transformação na argumentação de Melanchthon. Este deveria ser percebido como um processo de amadurecimento e de autonomia reflexiva. A pesquisa mostra que os eventos históricos foram bastante importantes para desencadear esse movimento. A partir deles foi percebida a necessidade de aperfeiçoamentos, os quais Melanchthon procurou realizar se mantendo fiel à sua compreensão do humanismo e à nova interpretação teológica advinda da Reforma.

\section{A doutrina dos Afetos e o Hábito}

\subsection{Afetos}

A doutrina dos afetos é um elemento do pensamento de Melanchthon cuja origem está na tradição filosófica que ele assume. Trata-se de um conceito que é desenvolvido por ele a partir principalmente de suas leituras de Aristóteles, Cícero e Agostinho. Mas estas leituras não são algo peculiar a Melanchthon. No ambiente humanista em geral se encontra essa tematização. No caso de Melanchthon, com ela acontece uma conjugação entre antropologia teológica e psicologia filosófica. Embora essa conjugação esteja explicitada de modo mais radical nos Loci de 1521, ela continua presente durante toda a carreira do autor.

Ralf Müller traça um quadro da importância dedicada para a discussão do conceito de afeto no contexto humanista da época. Principalmente Aristóteles e Agostinho (este último, no caso, a partir da noção de passiones) são bastante utilizados (MÜLLER, 2017, p. 23). Com isso, simultaneamente, mostra que se trata de um contexto em que a temática é trabalhada ecleticamente. Importante é que a apropriação mostra uma preocupação com a interioridade humana. A tendência geral nesse ambiente é que se use o conceito de appetitus sensitivus para os afetos sensíveis, compreendidos a 
partir da tradição aristotélica. Por outro lado, o appetitus intellectivus é entendido a partir da tradição neoplatônica e agostiniana. Melanchthon não utiliza estes conceitos em 1521 desta forma. O que ele faz é assumir o conceito aristotélico em sua versão ciceroniana, conjugando-a por sua vez com a doutrina do pecado original - ou seja, com um elemento agostiniano. Nos escritos mais voltados para o tema da ética, por outro lado, a importância de certos aspectos aristotélicos do conceito são realçados, como, por exemplo, a necessidade de ordenamento dos afetos pelo hábito (cf. MÜLLER, 2017, p. $37-43,128)$. Maurer $(1969$, v. 2, p. 248), paralelamente, destaca a apropriação do conceito aristotélico-estóico de afeto no contexto psico-antropológico como o outro lado da apropriação da concepção de fundo platônico que configura a sua doutrina do Espírito. Para ele, a configuração conflitiva e desordenada dos afetos só pode chegar a uma resolução através da ação ordenadora que a força extática do Espírito desempenha. Os aspectos destacados por cada um dos autores mostram a conjugação de elementos de tradição aristotélica e platônica que são típicos daquele período exemplificada no caso específico de Melanchthon.

Que a doutrina dos afetos continuou central em Melanchthon mostram as referências a ela nas versões posteriores dos Loci, ainda que ela tenha sofrido alterações importantes no sentido da rejeição do determinismo antropológico nessas versões posteriores. Igualmente importante é o fato de que essa doutrina tenha continuado a ser desenvolvida paralelamente, nos escritos filosóficos, sobre psicologia filosófica e sobre ética. Como a psicologia filosófica de Melanchthon é pensada teologicamente, o que ele ali afirma continua dando mostra da sua antropologia teológica. Assim, no Liber de anima ele define os afetos como desejos que estão no coração humano, de tal modo que os movimentos do coração antecedem o conhecimento humano. O conhecimento compreende uma dimensão também objetiva, mas a precedência da interioridade é um aspecto que não deve ser negligenciado (MELANCHTHON, CR 13, 124 e 129). Ou seja, embora aqui Melanchthon esteja tratando explicitamente do processo de apreensão, e não mais de uma fundamentação para os limites da liberdade da vontade, é notório que apesar da diferença há também uma continuidade que se manifesta na relevância de que a interioridade é dotada. Outro aspecto inovador em relação às suas primeiras elaborações está da apresentação de duas formas de governo da alma humana - a despótica, através do modelo da imposição legal, e a política, através da negociação e do convencimento retórico- 
racional (MELANCHTHON, CR 13, 130). Destacar este segundo modelo de governo interior é importante para se refletir sobre uma potencialidade de desenvolvimento da reflexão de Melanchthon que vá além de uma concepção de lei puramente impositiva. Novamente, cabe destacar que esse aspecto pressupõe uma ação do Espírito sobre a pessoa - tanto que ele admoesta, nesse texto filosófico sobre ética, à invocação da renovação divina (MELANCHTHON, CR 13, 131). Por outo lado, apesar de várias modificações, cabe destacar que ainda o Liber de anima continua, como os Loci de 1521, a afirmar - talvez com mais ênfase - que os afetos não são maus em si mesmos. Em 1521 era a sua desorganização que era ocasião para o mal, o que ainda continua presente agora (MELANCHTHON, CR 13, 163-165). Mas, além disso, o fato de os afetos manifestarem valências variadas serve agora para contestar uma compreensão determinista da psique humana, sob a senha de um confronto com o estoicismo (MELANCHTHON, CR 13, 133-135).

\subsection{Intelecto e vontade}

Na formulação dos Loci de 1521, Melanchthon tinha compreendido os afetos a partir de duas faculdades humanas fundamentais, a do conhecimento e a da vontade, esta descrita ali como a capacidade de seguir ou evitar aquilo que se conhece. Esta definição é afim a de Gerson, na sua Theologia Mystica. Gerson, como Bernardo, tinha a intenção de priorizar a vontade em relação ao intelecto (MAURER, 1969, v. 2, p. 245-246). Ali, então, Melanchthon se apropria da psicologia que encontra em Gerson no sentido de afirmar o papel desagregador dos afetos, tanto sobre o intelecto quanto sobre a vontade, com a qual eles estão intimamente relacionados. Com isso ele desenvolve uma fundamentação de estilo "naturalista" para a limitação da vontade e, em consequência, para o pecado (MAURER, 1969, v. 2, p. 255). A intenção de dominar os afetos pela razão, entretanto, que também já tinha sido deixada em segundo plano por Cícero, em favor da abordagem mais pessimista de Sêneca, não encontra espaço nessa elaboração (MAURER, 1969, v. 2, p. 256257; MATZ, 2001, p. 45). ${ }^{8}$

Também no Liber de anima Melanchthon afirma os afetos como "movimento do coração ou da vontade que segue o conhecimento"

Que Matz (2001, p. 59) diga que a concepção de pecado de original foi tirada por Melanchthon da Escritura é uma afirmação que obscurece o fato de que determinadas concepções externas à Bíblia são utilizadas no processo de sua compreensão. Trata-se de mais um exemplo de como a importância da tematização filosófica pode ser diminuída. 
(MELANCHTHON, CR 13, 168). Agora, entretanto, ele o faz com uma apresentação que enfatiza a dimensão física do processo. Enquanto que a mente representa mais a imagem divina no ser humano, através do intelecto, da memória, do juízo, da razão em geral, os afetos são descritos como resultado do processo de contração e expansão do coração (CR 13, 165-171). Além disso, aqui ele também segue a nomenclatura filosófica de forma mais próxima, ao falar explicitamente de intelecto e vontade (CR 13, 139). Mas a mais importante modificação é que ele passa a utilizar a distinção entre os apetites inferiores, incontroláveis pela razão, e os afetos superiores, que a ela estão subordinados (CR 13, 122s). Nessa configuração, os afetos são appetitiones que não se geram por contato, mas a partir da cognição (CR 13, 124). A partir daí, também os raios da sabedoria divina, ou seja, o que antes vimos como a representação do conhecimento da lei natural inata ao ser humano, não estão localizados no âmbito da vontade, mas no do intelecto (CR 13, 139s). Esta reformulação é fundamental para ele poder aqui então afirmar a possibilidade de o juízo moral evitar aquilo que a vontade deseja (CR 13,141).

\subsection{Hábito}

Um outro conceito assumido é o de hábito. Assim, no Liber de anima estão enumerados os seguintes hábitos do conhecimento: A ciência, a arte, a prudência, a fé e a opinião. Este conceito é elaborado a partir dos estudos de Aristóteles, sendo entendido como um meio para a educação dos afetos. Trata-se de uma inclinação constante, ou de uma aplicação constante da vontade. No caso, a referência é ao conceito aristotélico de PROAÍRESIS (MELANCHTHON, 2008, p. 156-157; CR 16, 227). Nessa fase posterior, o espaço interior dos afetos, que se encontrava praticamente imune aos efeitos da vontade, passa a estar aberto à sua ação. Para tanto, a configuração física que se desenvolve no Liber de anima se mostra permeável à interconexão entre o Espírito e os afetos humanos, falando-se até de uma "mistura" entre eles (MÜLLER, 2017, p. 146, 148; cf. CR 13, p. 88-89).

Esta interação entre o hábito e os afetos, por sua vez, é ainda completada pela valorização agora também do conhecimento que se origina pela via dos sentidos. Se anteriormente este caminho era inteiramente descartado, agora ele passa a ser aceito. O que por sua vez não significa, entretanto, uma rejeição dos conhecimentos inatos. Estes continuam, como já apontado acima, um pressuposto para a noção de lei natural e para toda a atuação ética. Esta abertura para os sentidos significa, assim, 
uma complementação das vias de conhecimento que cria um espaço para a educação ética consciente. A tarefa do intelecto passa a ser a de relacionar o conhecimento exterior com os afetos interiores (MÜLLER, 2017, p. 149).

Além disso, nas pessoas piedosas também o Espírito Santo age na interioridade. Desta forma também este adquire uma dimensão por assim dizer epistemológica (cf. tb. supra). Porque ele excita os afetos do coração nesse processo de conhecimento e de ordenação de afetos. Esta ação do Espírito Santo sobre os afetos interiores já estava presente na concepção dos Loci de 1521. Ali, entretanto, ela servia para acentuar a debilidade da vontade e da própria razão, enquanto que agora a dinâmica entre Espírito divino (nas pessoas renascidas), afetos e intelecto humanos se desenvolve de forma interativa (cf. CR 13, 120-121). A prática da oração, por exemplo, pode levar à comunicação do Espírito, o que renova a pessoa e a sua interação com os seus afetos (MÜLLER, 2017, p. 148-149; cf. CR 13, p. 88-89).

Assim, percebe-se a importância de que é dotado o conceito de hábito nesse momento posterior. Ele serve à valorização do processo de formação humana, uma vez que está simultaneamente aberto à comunicação do conhecimento e ao desenvolvimento da piedade, que em última análise só pode provir da ação divina. A valorização da ética por parte de Melanchthon, em função das necessidades concretas que se encontram para a organização da vida comunitária eclesial, social e política, implicou nessa necessidade de reformulação teórica da concepção antropológica. A fonte para isso foi encontrada em Aristóteles. (MÜLLER, 2017, p. 173-174). Mesmo que no passado as ideias desse tivessem sido liminarmente rejeitadas, agora Melanchthon desenvolveu uma forma de assumir aspectos significativos de sua ética e integrá-los com o modelo platônico geral do conhecimento inato e com as noções também já anteriormente aceitas da lei natural e da teoria dos afetos em que a mediação de Cícero tinha sido fundamental. A compreensão da filosofia em termos retóricos e a orientação prática da mesma representam os elos que possibilitaram esse desenvolvimento, como se verá a seguir.

\subsection{Implicações para o tema da liberdade humana}

Nesse ponto o desenvolvimento dos pontos tratados tem consequências evidentes para a questão da liberdade. Possivelmente inclusive tenham sido feitos com o propósito de aclarar a dimensão da vontade. Em particular as tematizações feitas nos escritos sobre ética apresentam tal característica. 


\section{A liberdade da vontade como locus}

\subsection{Loci como método - tópica e sistemática}

A compreensão do pensamento de Melanchthon em geral e também da sua reflexão sobre a liberdade em particular é iluminada dando atenção ao seu método. Este se configura a partir do conceito de Loci, que se encontra no título das várias edições de sua obra sistemática mais importante e também é discutido em alguns textos teóricos específicos (cf. FRANK, 2017a, p. 166167, 174). Como o tema da liberdade configura um dos loci mais significativos na obra de Melanchthon, é importante finalizar sua discussão colocando-o em conexão com essa compreensão metodológica.

O pesquisador mais importante sobre esse assunto na obra de Melanchthon é Günter Frank, de forma que suas publicações receberão prioridade nesse contexto. Em texto de 2011, em que discute a questão relativa à muito comentada pretensão do jovem Melanchthon de publicar obras de ou sobre Aristóteles, Frank já mostra como este método de loci deve ser compreendido a partir do desenvolvimento que se inicia em Aristóteles. Em sua Tópica, este trata de um tipo de argumentação que tem natureza distinta da do silogismo apodítico. Nela, o objetivo é, através de premissas reconhecidas, alcançar o convencimento do interlocutor. A perspectiva é prático-persuasiva. Os tópoi representam, nesse sentido, elementos gerais que, pelo seu reconhecimento público, permitem a construção argumentativa. É este aspecto da tópica aristotélica que Cícero disseminou como fundamental, buscando aplicá-la em sua retórica com o objetivo de estabelecer as bases para a construção de um discurso confiável (FRANK, 2011a, p. 64). É a partir do pano de fundo aristotélico-ciceroniano que, no contexto humanista, a formulação dos loci é compreendida como a apresentação de pontos fundamentais que possibilitem, a partir de certo consenso básico, a persuasão. Trata-se, assim, do estabelecimento de bases argumentativas (Frank 2011a, p. 66; FRANK, 2017a, p. 159-160; FRANK, 2017d, p. 321-322). ${ }^{9}$ Nesse seu contexto mais próximo, por sua vez, Melanchthon encontrou uma discussão significativa sobre o tema em andamento. Ele mesmo relatou com efusividade a importância da obra de Rodolfo Agricola em sua juventude, como ainda será tratado abaixo em conexão com o tema da retórica. Frank, entretanto,

9 O que, por outro lado, evidentemente também não pode ser simplesmente identificado com a concepção de ciência de Aristóteles, que buscava conceitos analíticos gerais (FRANK, 2017d, p. 329) 
aponta que, apesar disso, é necessário atentar também para peculiaridades na concepção de Melanchthon em relação à de Agricola: Trata-se da distinção entre loci dialéticos e loci retóricos. Exemplos Frank traz referindo à segunda versão de Dialectices libri quatuor, de 1528 e a Erotemata dialectices de 1547. Daí que na teoria argumentativa Melanchthon enquadre a dialética na retórica. Nesse sentido, ele entende que a concepção de loci em Melanchthon, apesar daquela sua manifestação efusiva tão notada na pesquisa em geral, não pode ser compreendida só a partir da apropriação feita por Agricola. Na verdade, ele estava profundamente a par da compreensão mediatizada pela tradição de Cícero e de Boécio (Frank 2011a, p. 69-70; FRANK, 2017a, p. 172-173; FRANK, 2017d, p. 322-324, 326). ${ }^{10}$

O importante é a consciência metódica que a concepção de loci forneceu a Melanchthon. A partir dela se criou a base para a organização sistemática de sua obra. Wiedenhofer afirma que a partir dessa definição metodológica de Melanchthon, que estava em conexão com o humanismo e em contraposição ao logicismo escolástico, se desenvolveram os temas, os quais ele abordou a partir de motivos distintos, que inspiraram a sistematização: científico-hermenêutico, pedagógico, crítico-apologético, eclesiológico. (WIEDENHOFER, p. 384-386).

Frank (2011b, 2011, p. 261-263; cf. tb. 2017a, p. 169) também apresenta como essa apropriação de Melanchthon se desenvolveu em três sentidos aplicados ao termo loci em sua obra: a) Primeiro, como sedes argumentorum, no sentido de Cícero - estes não são aleatórios, mas elaborados a partir de definições gerais ou da demonstração de causas; b) a partir desse uso, o termo também significa os princípios gerais de cada disciplina, os quais são derivados daquelas definições ou causas; c) substratos semânticos das ciências relativos aos objetos e temas tratados, que significam o processo de abstração a partir de textos fundamentais - sendo então esta concepção que permitiu

10 Sobre a evolução de Melanchthon quanto a isso, cf. FRANK, 2017d, p. 327: Na Dialética de 1520 Melanchthon ainda seguia o método da inventio e do iudicium de Agricola, na de 1547 a dialética assume, em primeiro lugar, a função judicativa a partir da argumentação silogística. A tópica com a inventio fica só em segundo lugar. „Die Dialektik. Melanchthons als allgemeine Wissenschaftslehre kann man als eine topisch erweiterte Analytik bezeichnen, als deren formale Beweismittel dann der demonstrative, dialektische und sophistische Syllogismus sowie das Enthymem fungieren, wie dies Aristoteles in der Ersten Analytiken entwickelt hatte." [“A dialética de Melanchthon, enquanto uma doutrina geral do conhecimento, pode ser caracterizada por uma analítica estendida topicamente. Como seus meios de comprovação formal operam então o silogismo demonstrativo, o dialético e o sofístico, assim como o entimema, tal como Aristóteles o tinha desenvolvido na Analítica Primeira.’] 
a Melanchthon pensar a sua dogmática como fundada sola scriptura, pois os princípios gerais são abstraídos do texto bíblico. Trata-se, assim, de método extremamente flexível e também enciclopédico (cf. tb. FRANK 2012, p. 70; FRANK, 2017d, p. 328). Além disso, essa mesma metodologia foi utilizada para a reorganização - e, consequentemente, a reinterpretação - da ética aristotélica. Esta exposição foi reestruturada de modo a poder ser entendida a partir da dinâmica entre lei e evangelho, ficando assim imune às críticas de Lutero e do próprio Melanchthon de 1521 (FRANK 2017b, p. 463-464). Igualmente os escritos sobre filosofia natural de Aristóteles foram abordados a partir da mesma perspectiva (FRANK, 2017a, p. 173).

No caso dos loci communes, Frank ressalta que o terceiro sentido é determinante. Aqui trata-se, em suas próprias palavras, de “[...] conceitos guia relativos aos conteúdo e relacionados ao tema de cada disciplina que não são tratados na dialética, mas na retórica. Mas enquanto tais 'loci communes' são em conjunto as partes principais (praecipua capita) de cada ciência." (FRANK, 2017a, p. 169-170) ${ }^{11}$. Este modelo já tinha sido estabelecido no seu De rhetorica libri tres de 1519. Esta observação é importante, porque a partir dela se tem uma compreensão melhor de como se dá o uso da Bíblia no processo de elaboração sistemática. Alguns autores, ao se referirem aos Loci de Melanchthon, fazem questão de meramente acentuar a origem bíblica e o princípio sola scriptura como referências. A apresentação de Frank mostra como, ainda que haja ênfase no princípio escriturístico por parte de Melanchthon, é fundamental perceber que para que ele se efetive é necessário um determinado modelo interpretativo, o qual, no caso, tem um histórico na tradição filosófica e retórica, sem o qual a forma como se aplica o referido princípio escriturístico não é corretamente compreendida. No caso, trata-se de um modelo que busca estabelecer os princípios gerais da interpretação bíblica não a partir de uma argumentação meramente lógica, mas a partir da consideração dos conteúdos e da sua estruturação temática ("sachbezogene Leitbegriffe"). A partir daí a discussão dos temas de inspiração bíblica é sistematicamente desenvolvida (FRANK, 2017a, p. 174-175; cf. tb. WRIEDT, 2017, p. 145). ${ }^{12}$

11 "[...] inhaltliche und sachbezogenen Leitbegriffe jeder Wissenschaft, die nicht in der Dialektik, sondern in der Rhetorik behandelt werden. Als solche sind ,loci communes“ aber insgesamt die herausragenden Bestandteile (praecipua capita) einer jeden Wissenschaft.“

12 Esse tema é importante também para se refletir sobre a distinção entre o modelo teológico de interpretação de Melanchthon e princípios fundamentalistas, por exemplo. Por mais que Melanchthon ainda vivesse antes da época da crítica moderna, sua intenção era 
Isso, por sua vez, aponta para a dimensão pragmática da proposta de Melanchthon, que ainda será aprofundada adiante. Assim como os loci representam os conceitos estruturantes de uma teologia que se baseia na proclamação bíblica, eles também se destinam não simplesmente a especulações, mas à disseminação de um conhecimento que tem uma finalidade prática - no caso, com ênfase na proclamação da graça e na promoção de uma vida eticamente digna (FRANK, 2017a, p. 172-173). O fato de que a sistematização teológica visa também a comunidade erudita deve igualmente ser compreendido nesse sentido. Porque a discussão sobre a relação entre a teologia e a racionalidade, sendo um tema árido, pressupõe uma erudição que não é imediatamente compartilhada por todos, mas é exigida pelos que se perguntam pelas questões de fundo (cf. FRANK, 2017a, p. 175-176). Ou seja, mesmo a discussão altamente especializada continua remetida a uma necessidade humana prática.

No contexto dessa preocupação pragmática, é importante ressaltar a noção de ciência que o modelo em questão pressupõe. O fato de que Melanchthon compartilhe com os humanistas em geral a crítica a uma ciência meramente especulativa, fundada na lógica, não significa de modo algum um desprezo pela busca da verdade. Em primeiro lugar, porque se trata de uma recuperação de uma noção de Aristóteles que tinha sido deixada em segundo plano, quando da sua retomada no século 13. Não deveria ser considerado que a tópica leve a um tipo de verdade inferior, mas a um outro tipo de temática, baseada na realidade concreta, conflitiva - como é o caso dos discursos argumentativos. Não se trata de demonstração apodítica, mas de persuasão a partir de princípios aceitos de forma geral (FRANK, 2017d, p. 322-324; cf. tb. WEAVER, 2017, p. 545). Em segundo lugar, porque o rigor argumentativo é mantido. Trata-se não de um abandono da dialética ou da lógica, mas de sua aplicação com finalidade prática. Além do emprego

empregar um modelo de interpretação em que buscava os tópicos fundamentais a partir da estruturação dos conteúdos textuais, não simplesmente a partir de princípios dogmáticos irrecusáveis a priori. Uma outra consequência para a exegese bíblica é apontada por Wengert (1998, p. 59-60): Também os seus comentários bíblicos se guiam pelo método dos loci, de maneira que não importa para Melanchthon tratar de todos os detalhes que se encontram num texto e nem mesmo de todos os seus versículos, mas sim dos temas estruturantes. Wiedenhofer, por outro lado, ao enfatizar a sistematicidade da teologia de Melanchthon, aponta para dois sentidos de summa em sua obra: por um lado núcleo, centro, essência e por outro síntese, resumo, o que se conjuga com o método enquanto modo de exposição e apresentação do que é essencial (WIDENHOFER, 1971, p. 391-392). Cf. mais sobre a hermenêutica bíblica em Melanchthon infra no ponto sobre retórica. 
persuasivo já citado, também a proposição de um novo gênero retórico por Melanchthon, o didaskalikón, deve ser compreendido nessa direção (FRANK, 2017d, p. 326-327; WRIEDT, 2017, p. 146).

Por fim, cabe referir ainda o caráter aberto desse método. A rigor, o aprofundamento da análise dos textos e das questões envolvidas faz com que os loci sejam infinitos. Daí a importância de perspicácia do sistematizador. Nesse sentido, trata-se de um modelo que exige criatividade, e que, portanto, Frank (2017a, p. 176) caracteriza como "enciclopédico". De modo semelhante, Wriedt fala de um método continuamente renovador, considerando por isso inclusive inadequada a pecha de iniciador da escolástica protestante que lhe é atribuída (WRIEDT, 2017, p. 146).

\subsection{Retórica e Inventio}

Em seu De inventione dialectica, Rodolfo Agricola apresenta como em cada discurso devem ser distinguidas três perspectivas: a intenção do autor (daí a importância da gramática), a aceitação do receptor (daí o valor da retórica) e a credibilidade do que é dito (daí a necessidade da dialética). A dialética, por sua vez, para ele deveria ser subdividida entre o momento da inventio e o do iudicio. Na obra em questão, entretanto, ele só desenvolveu a primeira das duas (FRANK, 2011b, 258). Mesmo assim, esta obra póstuma publicada no início do século 16 exerceu grande influência no círculo dos humanistas, inclusive, no caso, sobre Melanchthon. O entusiasmo deste com a leitura da obra deve ser entendido no contexto da superação de um conhecimento meramente argumentativo-lógico, como os humanistas entendiam ser a perspectiva escolástica (quanto a Erasmo, por exemplo, cf. FRANK, 2011b, p. 259). Em lugar disso, se visava uma conjunção entre a dialética e a retórica, tendo em vista uma dimensão prática do conhecimento. Nesse sentido, o modo de Agricola desenvolver a inventio nessa sua obra foi um elemento importante para a conjunção que viria a ser feita por Melanchthon entre retórica, dialética e perspectiva prática do conhecimento (FRANK, 2011b, p. 257). Ou seja, a dialética não deveria ser entendida primordialmente a partir da lógica (cf. WEAVER, 2017, p. 537, 541, 543). Pode-se dizer, assim, que com a inventio se encaminha uma dimensão criativa do processo de conhecimento, assim como a interação entre dialética e retórica o encaminha para sua efetivação através da linguagem e para a sua dimensão prática. Deste modo há aqui um ponto de partida para a questão da interpretação (WEAVER, 2017, p. 542). 
Um primeiro objetivo colocado para a retórica em Melanchthon é a compreensão das ideias. Isso se harmoniza tanto com a centralidade da palavra na proclamação protestante quanto com a importância da dimensão pedagógica no humanismo. Daí necessidade de clareza, ao contrário da valorização de certa obscuridade que se encontrava entre os humanistas italianos (WIEDENHOFER, 1976, v. 1, p. 434). Isso não significa, entretanto, que se deva simplesmente desprezar a estética da fala. Ela é importante no sentido de que para a boa expressão é necessário um conhecimento profundo da língua, o que permite nuances que expressam de modo mais claro a intenção (WIEDENHOFER, 1976, v. 1, p. 436-437). Um segundo objetivo tem relação com a persuasão. Nesse sentido, trata-se de conhecer os recursos da linguagem e empregá-los para conseguir mover os afetos. Assim, há necessidade de reconhecer uma dimensão comunicativoobjetiva e uma dimensão afetivo-poética na linguagem, e o bom exercício dela exige um equilíbrio entre ambas. Daí advém a capacidade de persuasão, em que o segundo elemento é importante (WIEDENHOFEN, 1971, p. 438-440; para relação com a interpretação de Aristóteles, cf. MAURER, 1967, v. 1, p. 198).

A partir da inventio há uma conjugação entre a recepção do conhecimento passado (cf. topoi/loci), o aperfeiçoamento do falar e aperfeiçoamento do juízo (prudentia). Ler os clássicos, por exemplo, simultaneamente melhora a compreensão, a linguagem e a moral. É a unidade do conhecimento do bem falar e do bem julgar que constitui o ser humano. Sendo ser de fala, esta possibilidade é a que o caracteriza, mas, ao mesmo tempo, o obriga - bem falar e bem julgar são condição contínua do tornar-se humano (WIEDENHOFER, 1976 , v. 1, p. $440-443) \cdot{ }^{13}$

Assim, através da perspectiva retórica, é possível reconhecer que a linguagem é mediadora entre a cultura recebida e sua transmissão ou ensino. A cultura é linguisticamente formada, sua apropriação exige o domínio da linguagem e sua transmissão é mediada linguisticamente, desenvolvendo a humanidade dos que aprendem (WIEDENHOFER, 1976, v. 1, p. 448449). Diferentemente de Aristóteles, como em Melanchthon não há uma tematização da ontologia, ele não discute a relação entre a palavra e o ser, o que também está ligado com a ausência de uma teoria da linguagem em sua obra. Assim como ocorre com outros humanistas, a preocupação de

13 Para a discussão dos gêneros apresentados por Melanchthon na inventio, cf. WEAVER, p. 541-545; para a relação entre inventio e tópos/locus, cf. WEAVER, p. 544. 
Melanchthon visa a dimensão histórica e cultural, não especulativa, da linguagem (WIEDENHOFER, 1976, v. 1, p. 449-450; cf. tb. FRANK, 1995, p. 163).

Na obra de Melanchthon, o exemplo primordial da importância da dimensão histórica se encontra nos princípios de interpretação da teologia (MAURER, 1969, v. 2, p. 487; cf. WEAVER, 2017, p. 543). ${ }^{14}$ O pano de fundo é a concepção de uma revelação divina transmitida nos textos - entendidos como pregações - recolhidos nas Escrituras. Esta também é a fundamentação para o entendimento de que os testemunhos bíblicos possuem objetividade, servindo assim de critério para a teologia e também de parceiros de diálogo com o ouvinte ou leitor (WIEDENHOFER, 450-456). Além disso, também o ideal de clareza retórica se encontra na compreensão da Bíblia. É a partir dele que se faz a crítica ao princípio alegórico de interpretação (cf. WEAVER, 2017, p. 544), a crítica ao ceticismo interpretativo (no que o veio reformatório de Melanchthon o contrapõe a outros humanistas, particularmente Erasmo) e a crítica a inovações históricas na Igreja não baseadas no testemunho bíblico. É nesse contexto que a interpretação (e, assim, a necessidade do conhecimento linguístico) ganha destaque. Ela se insere nessa compreensão que privilegia a historicidade (WIEDENHOFER, 1976, v. 1, p. 456-464). Toda essa reformulação dos princípios interpretativos, por sua vez, se dá a partir de dois loci fundamentais para o pensamento sistemático de Melanchthon em geral e a sua hermenêutica bíblica em particular: Lei e evangelho (WIEDENHOFER, 1976, v. 1, p. 464-467).

Daí também a base para a crítica da linguagem teológica, mais pontual no caso da patrística e mais generalizada no da escolástica. Originalmente o princípio não seria, pois, a busca de uma renovação interpretativa, mas, ao contrário, é o da preservação daquele testemunho que era entendido como a tradição verdadeira na história da igreja. O testemunho histórico original aparecia como guia seguro diante de um tempo de transformação e incerteza (WIEDENHOFER, 1976, v. 1, p. 468-471, cf. CR 1, 770).

\subsection{Implicações para a questão da liberdade}

O tema da liberdade é um dos tópicos trabalhados de forma constante na obra de Melanchthon. Trata-se de um dos temas que foi várias vezes

\footnotetext{
14 Uma outra possibilidade de exemplificação nesse sentido poderia se fazer a partir dos textos sobre história e literatura escritos por ele. Como tanto as narrativas históricas quanto as literárias são entendidas como recurso pedagógico para o desenvolvimento ético, eles também ilustram a valorização da mediação histórica propiciada por testemunhos que se oferecem sempre somente através da linguagem.
} 
abordado explicitamente como um tópico próprio, particularmente no que concerne a liberdade da vontade humana. Nesse sentido, trata-se também de um tema privilegiado para se examinar o desenvolvimento do pensamento dele. Mostra-se aí que Melanchthon estava aberto à reformulação de suas concepções. O pano de fundo teórico adotado da tradição retórica permite que se realce dois aspectos nesse processo de desenvolvimento da reflexão sobre a liberdade: a sua conexão sistemática com o conjunto de seu pensamento e a dimensão prática como horizonte dessa reflexão. É por isso que, apesar de apresentar um rigor argumentativo, uma especulação pura sobre a liberdade é descartada, como se vê ocorrer, por exemplo, no abandono do tema da predestinação.

\section{Conclusão}

A pesquisa sobre Melanchthon nos últimos tempos resgatou algo da importância da dimensão filosófica de sua obra e da importância desta no contexto da época. A partir dela se percebe que sua relevância está na reconfiguração da tradição filosófica passada a partir de uma nova estruturação compreensiva que surgiu no ambiente humanista e reformatório. Particularmente o tema da liberdade mostra sua relevância nesse sentido. A partir de elementos tomados da filosofia antiga, Melanchthon elaborou uma abordagem que colocou a tematização da liberdade como uma questão filosófico-religiosa importante para o âmbito da vida prática - no contexto da ética, da educação e da política. Este espaço ficou configurado sob a concepção teológica luterana denominada de "lei", mas tendo uma determinada autonomia em relação à esfera propriamente religiosa do "evangelho". Nesse sentido, trata-se de uma reflexão filosófica que, ainda que pré-crítica no sentido moderno, manifesta dois aspectos importantes: Por um lado ela demonstra uma preparação para a distinção das esferas civil e religiosa que se consolidaram na modernidade. Por outro, ela mostra como a tematização filosófica desse tema em princípio teológico foi um passo importante nessa direção.

\section{Referências}

BIHLMAIER, Sandra. Naturphilosophie. In: FRANK, Günter (Ed.) Der Reformator zwischen Glauben und Wissen. Ein Handbuch. Berlin : De Gruyter, 2017, p. 469-482. 
FRANK, Günter. Die theologische Philosophie Philipp Melanchthons (1497-1560). Erfurter Theologische Studient, Bd. 67. Leipzig : Benno, 1995.

FRANK, Günter. Praktische Philosophie unter den Bedingungen reformatorischer Theologie. Die Intellektlehre als Begründung der Willensfreiheit in Philipp Melanchthons Kommentaren zur praktischen Philosophie des Aristoteles. In: FRANK, Günter; LALLA, Sebastian (Hrgb). Fragmenta Melanchthoniana. Band 1. Zur Geistesgeschichte des Mittelalters und der frühen Neuzeit. Heidelberg : Verlag Regionalkultur, 2003, p. 243-54.

FRANK, Günter. Einleitung. In: MELANCHTHON, Philipp. Ethicae Doctrinae Elementa et Enarratio Libri quinti Ethicorum. (FRANK, Günter, Hrgb.). Stuttgart-Bad Cannstatt: Frommann-Holzboog, 2008, S. XIX-XLII.

FRANK, Günter. Accingimur enim non vano conatu ad instauranda Aristotelica Melanchthons Tübinger Plan einer neuen Aristoteles-Ausgabe. In: FUCHS, Franz. Der frühe Melanchthon und der Humanismus. Pirckheimer Jahrbuch 2011 für Renaissance- und Humanismusforschung, n. 25. Wiesbaden : Harrassowitz Verlag, 2011a, p. 51-71.

FRANK, Günter. Topische Dogmatik im Zeitalter der Konfessionalisierung: Philipp Melanchthon, Wolfgang Musculus, Melchor Cano. In: DINGEL, Irene; KOHNLE, Armin (Hrsg.). Philipp Melanchthon: Lehrer Deutschlands, Reformator Europas. Leipzig : Evangelische Verlagsanstalt, 2011b, p. 251-270.

FRANK, Günter. Melanchthon - der "Ethiker der Reformation”. In: Der Philosoph Melanchthon (FRANK, Günter; MUNDT, Felix, Hrgb.). Berlin : De Gruyter, 2012, S. 45-76.

FRANK, Günter. Die Topik als Methode der Dogmatik. Berlin : De Gruyter, 2017a.

FRANK, Günter. Praktische Philosophie. In: FRANK, Günter (Ed.) Der Reformator zwischen Glauben und Wissen. Ein Handbuch. Berlin : De Gruyter, 2017b, p. 457-467.

FRANK, Günter. Zum Philosophiebegriff Melanchthons. In: FRANK, Günter (Ed.) Der Reformator zwischen Glauben und Wissen. Ein Handbuch. Berlin : De Gruyter, 2017c, p. 451-456.

FRANK, Günter, Zum Wissenschaftsvertändnis: Melanchthons Topik. In: FRANK, Günter (Ed.) Der Reformator zwischen Glauben und Wissen. Ein Handbuch. Berlin : De Gruyter, 2017d, p. 321-331.

FRANK, Günter. Cicero in der Theologie der Frühen Neuzeit. Von Philipp Melanchthon bis Hugo Grotius. In: EUSTERSCHULTE, Anne; FRANK, Günter (Hrgb). Cicero in der frühen Neuzeit. Stuttgart-Bad Cannstatt : Frommann-Holzboog, 2018. Melanchthon-Schriften der Stadt Bretten 13. P. 167-190.

FRANK, Günter; LALLA, Sebastian (Hrsg.) Zur Geistesgeschichte des Mittelalters und der frühen Neuzeit. Fragmenta Melanchthoniana, Bd. 1. Ubstadt-Weiher: Verl. Regionalkultur, 2003. 
GERHARDS, Helmut. Die Entwicklung des Problems der Willensfreiheit bei Philipp Melanchthon. Inaugural-Dissertation zur Erlangung der Doktorwürde vorgelegt der Philosophischen Fakultät der Rheinischen Friedrich Wilhelms-Universitäat zu Bonn. Bonn, [1955].

GRAYBILL, Gregory B. Evangelical Free Will: Philipp Melanchthon's Doctrinal Journey on the Origins of Faith. New York : Oxford, 2010.

GROSSE, Sven. System der Theologie. In: FRANK, Günter (Ed.) Der Reformator zwischen Glauben und Wissen. Ein Handbuch. Berlin : De Gruyter, 2017, p. 333-345.

HEESCH, Matthias. Reformation oder Humanismus? Hans Emil Webers Würdigung Melanchthons. In: FRANK, Günter; KÖPF, Ulrich. Melanchthon und die Neuzeit. StuttgartBad Cannstatt, 2003, p. 215-222. Melanchthon-Schriften der Stadt Bretten 7.

HOLM, Bo Kristian, Theologische Anthropologie. In: FRANK, Günter (Ed.) Der Reformator zwischen Glauben und Wissen. Ein Handbuch. Berlin : De Gruyter, 2017, p. 395-407.

JUNG, Martin H. Prädestination, Eschatologie, Frömigkeit. In: FRANK, Günter (Ed.) Der Reformator zwischen Glauben und Wissen. Ein Handbuch. Berlin : De Gruyter, 2017, p. 439-450. 1. Prädestination.

KOLB, Robert. Innerprotestantische Streitigkeiten. In: FRANK, Günter (Ed.) Der Reformator zwischen Glauben und Wissen. Ein Handbuch. Berlin : De Gruyter, 2017, p. 109-124.

KÖPF, Ulrich. Melanchthons "Loci" und ihre Bedeutung für die Entstehung einer evangelischen Dogmatik. In: DINGEL, Irene; KOHNLE, Armin (Hrsg.). Philipp Melanchthon: Lehrer Deutschlands, Reformator Europas. Leipzig : Evangelische Verlagsanstalt, 2011, p. 129-152.

MATZ, Wolfgang. Der befreite Mensch: Die Willenslehre in der Theologie Philipp Melanchthons. Göttingen : Vandenhoeck \& Ruprecht, 2001.

MAURER, Wilhelm. Der junge Melanchthon. Göttingen : Vandenhock \& Ruprecht, 19671969, 2 Bd.

MELANCHTHON, Philipp. Annales vitae Phil. Mel. a. 1548-1552. In: BRETSCHNEIDER, Carolus Gottlieb, ed. Phillipi Melanthonis opera quae supersunt omnia. Corpus Reformatorum (CR), v. 7. Halis Saxonum : C. A. Schwetschke et filium, 1843.

MELANCHTHON, Philipp. Anales vitae Phil. Mel. a. 1557-1560. In: BRETSCHNEIDER, Carolus Gottlieb, ed. Phillipi Melanthonis opera quae supersunt omnia. Corpus Reformatorum (CR), v. 9. Halis Saxonum : C. A. Schwetschke et filium, 1843.

MELANCHTHON, Philipp. De artibus liberalibus. In: STUPPERICH, Robert. Melanchthons Werke in Auswahl. Bd. III: Humanistische Schriften. Gütersloh : Gerd Mohn, 1961, S. 17-28. 
MELANCHTHON, Philipp. Enarrationes aliquot librorum ethicorum Aristotelis. In: BRETSCHNEIDER, Carolus Gottlieb, ed. Phillipi Melanthonis opera quae supersunt omnia. Corpus Reformatorum (CR), v. 16. Halis Saxonum : C. A. Schwetschke et filium, 1843, col. 277-416.

MELANCHTHON, Philipp. Erotemata dialectices. In: BRETSCHNEIDER, Carolus Gottlieb, ed. Phillipi Melanthonis opera quae supersunt omnia. Corpus Reformatorum (CR), v. 13. Halis Saxonum : C. A. Schwetschke et filium, 1843, col. $507 \mathrm{ff}$.

MELANCHTHON, Philipp. Ethicae Doctrinae Elementorum libri duo. In: BRETSCHNEIDER, Carolus Gottlieb, ed. Phillipi Melanthonis opera quae supersunt omnia. Corpus Reformatorum (CR), v. 16. Halis Saxonum : C. A. Schwetschke et filium, 1843, col. 165-276.

MELANCHTHON, Philipp. Ethicae Doctrinae Elementa et Enarratio Libri quinti Ethicorum. (FRANK, Günter, Hrgb.). Stuttgart-Bad Cannstatt: Frommann-Holzboog, 2008.

MELANCHTHON, Philipp. Examen eorum qui audiuntur ante ritum publicae ordinationis, qua commendatur eis ministerium evangelii. In: BRETSCHNEIDER, Carolus Gottlieb, ed. Phillipi Melanthonis opera quae supersunt omnia. Corpus Reformatorum (CR), v. 23. Halis Saxonum : C. A. Schwetschke et filium, 1843, S. XXI-102.

MELANCHTHON, Philipp. Liber de Anima. In: STUPPERICH, Robert. Melanchthons Werke in Auswahl. Bd. III: Humanistische Schriften. Gütersloh : Gerd Mohn, 1961, S. 303-372.

MELANCHTHON, Philipp. Liber de Anima. In: BRETSCHNEIDER, Carolus Gottlieb, ed. Phillipi Melanthonis opera quae supersunt omnia. Corpus Reformatorum (CR), v. 13. Halis Saxonum : C. A. Schwetschke et filium, 1843, col. 1-178.

MELANCHTHON, Philipp. Loci Communes seu Hypotyposes Theologicae. In: BRETSCHNEIDER, Carolus Gottlieb, ed. Phillipi Melanthonis opera quae supersunt omnia. Corpus Reformatorum (CR), v. 21. Halis Saxonum : C. A. Schwetschke et filium, 1843, col. 83-228

MELANCHTHON, Philipp. Loci Communes theologici recens collecti et recogniti a Phil. Melanthone. In: BRETSCHNEIDER, Carolus Gottlieb, ed. Phillipi Melanthonis opera quae supersunt omnia. Corpus Reformatorum (CR), v. 21. Halis Saxonum : C. A. Schwetschke et filium, 1843, col. 361-560

MELANCHTHON, Philipp. Loci praecipui theologici nunc denuo cura et diligentia summa recogniti, multisque in locis copiose illustrati per Phil. Melanthonem. In: BRETSCHNEIDER, Carolus Gottlieb, ed. Phillipi Melanthonis opera quae supersunt omnia. Corpus Reformatorum (CR), v. 21. Halis Saxonum : C. A. Schwetschke et filium, 1843, col. 601-1101.

MELANCHTHON, Philip. Paul's Letter to the Colossians. Translated by D. C. Parker. Sheffield : Almond Press, 1989. 
MÜLLER, Ralf. Die Ordnung der Affekte: Frömmigkeit als Erziehungsideal bei Erasmus von Rotterdam und Philipp Melanchthon. Bad Heilbrunn : Julius Klinkhardt, 2017. (Tese apresentada na Faculdade de Psicologia e Pedagogia da Ludwig-Maximilians-Universität, Munique, 2015).

MUNDHENK, Christine. Rhetorik und Poesie im Bildungssystem Philipp Melanchthons. Lutherjahrbuch. N. 78 (BEUTEL, Albrecht, ed.). Göttingen : Vandenhoeck \& Ruprecht, 2011, p. 251-275.

NEUMANN, Hans-Peter. Dialektik. In: FRANK, Günter (Ed.) Der Reformator zwischen Glauben und Wissen. Ein Handbuch. Berlin : De Gruyter, 2017, p. 515-534.

PETERSON, Charles William. The Humanistic, Fideistic Philosophy of Philip Melanchthon (1497-1560). Dissertation Submitted to the Faculty of the Graduate School, Marquette University. 2012.

SCHNEIDER, Martin. Geschichte. In: FRANK, Günter (Ed.) Der Reformator zwischen Glauben und Wissen. Ein Handbuch. Berlin : De Gruyter, 2017, p. 577-590.

SPARM, Walter. Altes Reich. In: FRANK, Günter (Ed.) Der Reformator zwischen Glauben und Wissen. Ein Handbuch. Berlin : De Gruyter, 2017, p.

ULRICH, Claudete Beise; KLUG, João. Felipe Melanchthon (1497-1560): pedagogo da Reforma protestante, patrimônio da educação. Revista Brasileira de História das Religiões. Ano 7 , n. 24, jan.-abr. 2016, S. 149-170.

WEAVER, William P. Rhetorik. In: FRANK, Günter (Ed.) Der Reformator zwischen Glauben und Wissen. Ein Handbuch. Berlin : De Gruyter, 2017, p. 535-546

WENGERT, Timothy J. Human Freedom, Christian Righteousness: Philip Melanchthon's Exegetical Dispute with Erasmus of Rotterdam. New York, Oxford: Oxford University Press, 1998.

WIEDENHOFER, Siegfried. Formalstrukturen humanistischer und reformatorischer Theologie bei Philipp Melanchthon. Bern : Herbert Lang; Frankfurt a. M, München : Peter Lang, 1976. Teil 1: Text. Teil 2: Anmerkungen und Literaturverzeichnung. (Regensburger Studien zur Theologie).

WRIEDT, Markus. Bildung, Schule und Universität. In: FRANK, Günter (Ed.) Der Reformator zwischen Glauben und Wissen. Ein Handbuch. Berlin : De Gruyter, 2017, Ibid., p. 141-154.

Submetido em: 18-6-2020

Aceito em: 14-8-2020 